\title{
CORONAVIRUS
}

\section{Special care and new environments}

Sir, patients with autism and other special care needs often rely on familiar surroundings, processes and faces when attending the dentist to reduce the sensory burden and anxiety of being in the dental environment. Any change to the 'routine' of attending may present such patients with difficulties that the dental team should have awareness of and be sensitive to. We must make every effort to prepare patients for the changes to the dental environment that they are used to attending such as the increased use of PPE.

Sending photographs and advice of how layouts and processes may have changed within the practice and what to expect regarding PPE and infection control procedures ahead of their appointment to patients and carers could prove invaluable in maintaining both attendance for this potentially higher risk group, as well as talking through any new steps during their visit or procedure to maximise compliance. Technology can also be utilised to facilitate this, such as 360 degree photographs or video tours on practice websites or social media. Although aerosol generating procedures would ideally be carried out in a single visit, this may not be possible or practicable for this patient group.

Any additional barriers to attending for regular preventive dental care could have significant longer term risks to the dental health of this already vulnerable patient cohort. A decrease in regular professional preventive input risks increasing the need for invasive procedures and sedation or general anaesthesia, in turn increasing risks to both dental and general health. We must therefore do everything we can to minimise the impact of these changes for patients with special care needs.

S. Carr, South Tyneside, UK https://doi.org/10.1038/s41415-020-1786-1

\section{Povidone iodine gargle and mouthwash}

Sir, a recent letter in your journal by Challacombe et al. highlighted the potential of povidone iodine (PVP-I) mouthwash and nasal spray in reducing the risk of cross-infection of COVID-19 among the dentists and their assistants. ${ }^{1}$ The evidence used was based on in vitro data of PVP-I's virucidal activity against coronaviruses such as SARS-CoV and MERS-CoV. Here, we demonstrate in vitro virucidal activity of an oral PVP-I product against SARS-CoV-2, the virus causing COVID-19.

BETADINE Gargle and Mouth Wash in two concentrations, undiluted (PVP-I 1\% w/v) and at a $1: 2$ dilution (PVP-I $0.5 \% \mathrm{w} / \mathrm{v}$ ) was tested for virucidal activity ( $\geq 4 \log 10$ reduction in viral titres) against SARS-CoV- 2 in both clean $(0.3 \mathrm{~g} / \mathrm{l} \mathrm{BSA})$ and dirty $(3.0 \mathrm{~g} / \mathrm{l} \mathrm{BSA}+3 \mathrm{~mL} / \mathrm{L}$ human erythrocytes) conditions at time points of 15, 30 and 60 seconds in a BSL-3 laboratory of the Tropical Infectious Diseases Research and Education Center (TIDREC), University of Malaya, Malaysia. The SARS-CoV-2 was isolated and propagated in Vero-E6 cells in TIDREC. The cytotoxicity of the product to the Vero-E6 cells was evaluated and taken into account when performing the kill time assay. Virus kill time assay was performed based on the established EN14476 methodology. ${ }^{2}$ Virus titres were calculated as $50 \%$ tissue culture infectious dose (TCID50/mL) using the Spearman-Karber method. ${ }^{2}$ The study demonstrated that undiluted PVP-I achieved $>5 \log 10$ reduction in the virus titres at 15 ,
30 and 60 seconds treatment exposure under both clean and dirty conditions. In contrast, when PVP-I was tested at 1:2 dilution a $>4$ $\log 10$ kill at 15 seconds and $>5 \log 10$ kill at 30 and 60 seconds in comparison to control was seen in both clean and dirty.

Dental practice poses a potential risk of COVID-19 cross-infection among patients, dentists and their assistants through direct exposure to saliva and indirect contact through contaminated instruments. ${ }^{3}$ Several associations, including the Australian Dental Association, have recommended using a preprocedural mouthwash with products such as povidone iodine. ${ }^{4}$ In our study, we present direct evidence of the virucidal activity of PVP-I gargle and against SARS-CoV-2 in just 15 seconds. In today's scenario, PVP-I gargle and mouthwash could be an adjuvant to PPEs in reducing the risk of COVID-19 transmission in healthcare practices, especially when oral interventions are warranted, such as in dental practice.

P. Hassandarvish, V. Tiong, A. B. Sazaly, Malaya, Malaysia; N. A. Mohamed, Kuala Lumpur, Malaysia; H. Arumugam, A. Ananthanarayanan, M. Qasuri, Y. Hadjiat, Singapore

\section{References}

1. Challacombe S J, Kirk-Bayley J, Sunkaraneni V S, Combes J. Povidone iodine. Br Dent J 2020; 228: 656-657.

2. $M$, Koburger-Janssen T, Eickmann $M$, Zorn J. In vitro bactericidal and virucidal efficacy of povidone-iodine gargle/mouthwash against respiratory and oral tract pathogens. Infect Dis Ther 2018; 7: 249-259.

3. Fallahi H R, Keyhan S O, Zandian D, Kim S-G, Cheshmi B. Being a front-line dentist during the Covid-19 pandemic: a literature review. Maxillofac Plast Reconstr Surg 2020; 42: 12.

4. Australian Dental Association. Managing COVID-19 guidelines. Available at: https://www.ada.org.au/ Campaign/COVID-19/Guide-to-Managing-COVID-19/ ADA-Managing-COVID-19-Guide-v-2.aspx (accessed 3 June 2020).

https://doi.org/10.1038/s41415-020-1794-1 